\title{
28 Research Suare \\ Vocabularies And Rituals of Climate Grief In Canada: A Typology
}

Melanie Zurba ( $\square$ Melanie.Zurba@Dal.ca )

Dalhousie University https://orcid.org/0000-0001-8411-6083

\section{Sara Boyd}

Dalhousie University

\section{Bryanne Lamoureux}

Dalhousie University

\section{Erica Mendritzki}

NSCAD University

\section{Andrew Park}

The University of Winnipeg

\section{David Busolo}

University of New Brunswick

\section{Lisa Binkley}

Dalhousie University

\section{Roberta Woodgate}

University of Manitoba

\section{Research Article}

Keywords: Climate grief, climate change, mental health, wellbeing, scoping review, Canada, typology, solastalgia

Posted Date: February 7th, 2022

DOl: https://doi.org/10.21203/rs.3.rs-1296876/v1

License: (c) (i) This work is licensed under a Creative Commons Attribution 4.0 International License.

Read Full License 


\section{Abstract}

Climate change has become a reality for many people across Canada. Environmental changes occurring in Canadian ecoregions include: increasing temperature, more severe storms, increasing wildfire occurrence, and decreasing sea ice thickness and duration. These events are impacting mental health due to the psychological experience of grieving and loss associated with climate change. In this study, we use the term 'climate grief' to describe the feelings connected to both the experienced and anticipated loss due to climate change. The purpose of this study was to explore the different ways that Canadian's express and process climate grief. A scoping review was conducted to create a typology of existing vocabularies and rituals for expressing and processing climate grief. The results of the typology found that the primary types included peer-reviewed research, media, religious/spiritual practices, education, mental health support, social action gatherings, grey literature, guiding frameworks, and artistic expression. Secondary types included 25 subtypes and 37 tertiary types/approaches. It is important for governments and medical boards to have a proactive and not a reactive position in regard to mental and physical health effects from climate change. The way that people express and process feelings associated with climate change can provide important insights for developing climate change policy and programs. Furthermore, climate change strategies should include recognition of psychological wellbeing.

\section{Introduction}

Climate change is having a profound impact on how people interact with and perceive the natural environment. Alongside increasing severity and occurrence of climactic events such as drought, heatwaves, and storms, Canadians are witnessing more wildfires, flooding, and coastal erosion (IPCC 2019). These events have in many cases exacerbated the ongoing issues of habitat loss, damage to infrastructure, and socio-economic inequality (IPCC 2019; Richards 2018). Higher temperatures are an increasing concern for Canadians as Canada warms at more than double the global rate, with the Canadian Arctic warming at approximately three times the global rate (Bush and Lemmen 2019). Many northern communities that depend on sea ice are experiencing the effects of decreased sea ice thickness and extent, rising sea levels, and changes in flora and fauna (Cunsolo-Willox et al. 2013). Forest fires are becoming more difficult to control and are causing more damage due to climate change increasing the occurrence of high winds and drought (NRC 2020). In 2018, British Columbia saw a record-breaking fire season, while in 2019 Alberta, Ontario, and the Yukon saw higher than average burn areas which led to numerous community evacuation (NRC 2020). Other severe impacts evident in Canada's ecoregions include unpredictable and extreme weather events and an increase in invasive species (Bush and Lemmen 2019). These events affect Canadians' physical environment, as well as the mental and emotional health of the nation's population (Thurton 2017).

As a response to the increasing impact of climate change, various terms have emerged to describe the unique emotional and psychological states experienced by those affected by such events. In 2005 , the Australian philosopher Glenn Albrecht coined the term solastalgia to describe the effects of long-term droughts on the emotional and mental wellbeing of farmers in New South Wales (Albrecht 2005). 
Solastalgia describes the sense of emotional or psychic distress connected to negative changes in one's home environment (Albrecht 2005). A similar term, made popular by the Canadian researcher Dr. Ashlee Cunsolo, is ecological grief. She used this term for her research on Inuit communities in Northern Labrador as they were experiencing ongoing loss of sea ice (Cunsolo and Ellis 2018). Ecological grief has been defined as "grief in relation to experienced or anticipated ecological losses, including the loss of species, ecosystems and meaningful landscapes due to acute or chronic environmental change" (Cunsolo and Ellis 2018 p.275). Climate grief has been used as a synonym for ecological grief but also as a more general term to capture generalized climate-related anxiety (Bryant 2019; Pihkala 2020). Other related terms include anticipatory grief and pre-traumatic stress disorder, terms which attempt to capture feelings associated with the predictions of change and loss in the future (Cunsolo and Ellis 2018).

In French-Canadian discussions ${ }^{[1]}$, these feelings of anxiety are frequently expressed with the term écoanxiété (sometimes spelled éco-anxiété). Its direct English translation, ecoanxiety (sometimes spelled eco-anxiety or eco anxiety), combines the words ecology and anxiety to describe the apprehension, stress, and feelings of anxiety that occurs due to anticipated threats related to a changing and uncertain climate (Albrecht 2011; Cunsolo et al. 2020). The term solastalgie (also spelled solastalgia) - a direct translation of Albrecht's (2005) term solastalgia, and deuil écologique - a direct translation of ecological grief (Cunsolo and Ellis 2018), are also used to describe the psychological experiences of grief and loss. Throughout this research, we offer direct translations of French terminology; however, we acknowledge there are limits to translating terms outside their language of origin, as certain terms may be interpreted differently when articulated in different languages. Language posits a descriptive power that can be reduced through the process of translation, especially when generating translations that extend from nature to science to emotional expression through words (Kimmerer 2013 p.48-49) Although aware of these limitations, we offer these direct translations to clearly communicate our findings in English, while offering specific information in French to distinguish its unique linguistic context in Canada. During our search in both languages, we also looked for terminology expressing such emotions in Indigenous languages, but did not find any reference to terminology that directly describes this experience.

Currently, there is no universally-used, formally recognized term for the psychological experience of loss and grieving associated with climate change, as is the case for other psychological states (e.g. PTSD). Although there is growing awareness of these experiences, there is a lack of research into how Canadians experience climate grief, and how these experiences are expressed. Our primary objective in this paper is to achieve an improved understanding of climate grief by creating a living typology of the vocabularies and rituals associated with Canadians' reactions to, processing of, and outward expression of climate grief. For the rest of this report, we will use climate grief as an all-encompassing term to mean the experienced and anticipated grief, loss, and mourning associated with the effects of climate change. We acknowledge that this experience is complex, multi-faceted, and not easily quantifiable. The living typology presented in this paper will continue to evolve as Canadians reckon with climate grief, and as our collective understanding of the phenomenon improves. 
[1] Canada has two official languages, English and French. Many Indigenous and newcomer languages are also spoken in Canada.

\section{Methods}

Since climate grief is a relatively new concept, we decided that a scoping review would be the most useful method of research. Scoping reviews are commonly used to examine the range and extent of research material associated with a research question in order to provide a preliminary map of the literature (Arksey and O'Malley 2005). This review allowed us to get a snapshot of vocabularies and rituals of climate grief across disciplines and provided us with a better understanding of how to continue our research in this area. Since the official languages of Canada are English and French, this research was conducted in both languages. We also looked for sources in Indigenous languages from the territory currently known as Canada; however, no sources were found. The scoping protocol for this study was drafted using the five-stage framework created by Arksey and O'Malley (2005). The five stages are (1) identifying a research question, (2) identifying relevant databases, (3) study selection, (4) charting and coding the data, and (5) collating, summarizing, and reporting the results. Our methodology is organized and described according to these stages.

\subsection{Stage 1: Identifying the research question}

This study is part of a larger study titled Creating Vocabularies and Rituals for Climate Grief Through Multiple Knowledge Systems and the Artistic Process, which is led by Canadian researchers based at Canadian Universities.[1] For this study, our principal research question was: What are the existing vocabularies and rituals for reacting to, expressing, and processing grief associated with climate change in Canada? We define vocabularies as 'constituting means of communication or expression, such as different types of oral or written communication and expression through arts or crafts. We define rituals as 'a set of actions and/or words done in accordance with religious customs, social customs, or normal protocol'. These definitions were kept broad in order to include a wide range of sources. In addition to being the country of residence of the research team, Canada was chosen as our study area because it is warming at twice the global rate and the northern region is warming at three times the global rate (Bush and Lemmen 2019). Hence, this study can help us better understand how the nation's population expresses loss related to various ecoregions that are sensitive to climate change. It is important to note that those living in Canada may also express and process climate grief from climate change affecting other parts of the world.

\subsection{Stage 2: Identifying relevant databases}

This stage involves the decision process of choosing appropriate databases and media. Advice for which databases and search methods to use are discussed with the climate grief project team, two Dalhousie University liaison librarians who focus on subjects on sciences, management, arts, and languages, and two librarians from NSCAD University (formerly known as the Nova Scotia College of Art and Design). 
Following these conversations, we chose to search electronic databases, reference lists, the contents of key journals/national media companies/popular social media platforms, and existing networks/organizations. A detailed list of the databases that were searched can be found in Table 2 . Discrepancies between databases in Table 1 and 2 for French and English are due to the languagespecific nature of the sources or lack of English/French examples in these databases.

\subsection{Stage 3: Study Selection}

To find examples appropriate for the research question, different search methods were used for each type of database. Search terms were chosen based on a preliminary literature search on the grieving and mourning associated with climate change. Climate grief, ecological grief, and solastalgia were the most common English terminologies found and are thus used in our search. Since we have less knowledge on what terms are used in French to describe climate grief, a basic Google search of "changement climatique" AND "santé mentale" (climate change AND mental health) was completed and the first 100 results were reviewed thoroughly. This preliminary search revealed that the more familiar terms used in English were also being employed in French in their translated states. As a result of these findings, the French search protocols closely followed the protocols for the English search while leaving room for new terms to emerge. The only additional term used in the French search was "écoanxiété", which we added during the search of online media databases, when it became evident that this term was being used in French to refer to grief and other emotions related to climate change. Table 1 shows the Boolean operators and search terms entered in each database.

In addition, we looked through the bibliographies of studies found through our search approach as described above, and investigated artists and organizations referenced in media pieces we encountered during our search. We excluded articles and websites written in languages that were not English or French, websites with expired links, and articles that were inaccessible. Only content made by people who

think of themselves as Canadians or as inhabitants of the political-geographic land of Canada ${ }^{[2]}$ were included. Since the concept of climate grief is still very new to academic and public discourse, no date restrictions were put on the search criteria.

Table 1. Search protocol for English sources 


\begin{tabular}{|c|c|c|}
\hline Sources & Search & Search Terms \\
\hline $\begin{array}{l}\text { A. Web of Science, Scopus, Novanet, University of } \\
\text { Saskatchewan's Indigenous Studies Portal, Science } \\
\text { Direct, Art and Architecture, Canadian Psychology } \\
\text { Association, Jstor, Google Scholar }\end{array}$ & $\begin{array}{l}\text { All } \\
\text { searches }\end{array}$ & $\begin{array}{l}\text { "climate grief" OR "eco* } \\
\text { grief" OR "solastalgia" OR } \\
\text { "Canad* AND ("climate } \\
\text { change" AND "mental } \\
\text { health")" }\end{array}$ \\
\hline \multirow{5}{*}{$\begin{array}{l}\text { B. Canadian Broadcasting Corporation (CBC), National } \\
\text { Film Board of Canada (NFB), the Globe and Mail, } \\
\text { Alternatives Journal, The Walrus, Border Crossings, } \\
\text { Canadian Art Magazine, Twitter, Instagram, Facebook, } \\
\text { and Reddit }\end{array}$} & \multirow{5}{*}{$\begin{array}{l}\text { All } \\
\text { searches }\end{array}$} & "climate grief" \\
\hline & & "eco-grief" \\
\hline & & "ecological grief" \\
\hline & & "solastalgia" \\
\hline & & $\begin{array}{l}\text { "climate change and } \\
\text { mental health" }\end{array}$ \\
\hline \multirow[t]{5}{*}{ C. Dalhousie Eco-Art Interactive map } & \multirow{5}{*}{$\begin{array}{l}\text { Title, } \\
\text { theme, and } \\
\text { statement } \\
\text { of purpose } \\
\text { were } \\
\text { scanned. }\end{array}$} & "climate grief" \\
\hline & & "solastalgia" \\
\hline & & "ecological grief" \\
\hline & & $\begin{array}{l}\text { (("climate change" OR } \\
\text { "Anthropocene") AND } \\
\text { ("grief" OR "mourning" OR } \\
\text { "loss")) }\end{array}$ \\
\hline & & $\begin{array}{l}\text { "climate change" AND } \\
\text { "mental health" }\end{array}$ \\
\hline
\end{tabular}

Table 2. Search protocol for French search 
Search

All

A. CBCA Complete, Erudit, Eureka, Google Scholar, GREENFile PsychInfo, Scopus, Social Sciences \& Art \& Humanities, Social Work Abstracts

B. CBC Radio Canada, La Press, Le Devoir, La Liberté, Le Franco, L'Acadie Nouvelle, Le Courrier de la Nouvelle-Écosse, Le Voyageur, L'Express de Toronto, Facebook, Twitter, Reddit, Instagram

All searches

C. Google Images ${ }^{[1]}$, Dalhousie Eco-Art Interactive map searches

All

\section{Search Terms}

("deuil écologique" OR "solastalgi*) (Canad* AND ("changement climatique" AND "santé mentale"))

"deuil écologique"

"solastalgia"

"solastalgie"

"changement climatique et santé mentale". "écoanxiété" searches.

"deuil écologique"

"solastalgia"

"Solastalgie"

"changement

climatique et santé mentale", "écoanxiété"

\subsection{Stage 4: Charting and coding the data}

From the criteria above, a total of 129 sources were chosen. The sources were charted first using the database programme Microsoft Excel. This allowed for both a collection of bibliographic data and for general information to create a working mind map for the typology. Information that was collected from journals, web, and news articles includes; author(s), title, year of publication, location, abstract/artist statement/brief description, keywords (if available), type of source, and potential vocabulary or ritual. For artworks, the information collected includes; artist(s), title, year created, medium, location, and potential vocabularies and/or rituals.

We used the qualitative data analysis software Nvivo to categorize and code the sources into different nodes. To develop the typology, we applied an emergent (inductive) process, whereby selected studies were coded into lower level categories based on the specific medium through which vocabularies or rituals were found (e.g., painting, drawing) before being grouped under higher order headings (e.g., visual arts) (Elo and Kyngas 2007). This resulted in three node levels to construct the typology of vocabularies and rituals: Themes, types, and subtypes. The primary level identifies high-level, distinct, overarching themes for the mediums through which climate grief vocabularies and rituals were being expressed in our selected studies (e.g., artistic expression). The secondary level, types, identifies varying mediums of expression (e.g., visual arts) within each theme. The tertiary level is more detailed and identifies specific subtypes (e.g., painting, drawing) included within the identified types. These subtypes, then types and 
themes, emerged as each source was coded. They were also reviewed and reworked multiple times to ensure that each coding level and each code within a level were distinct and descriptively accurate.

Additionally, climate grief terminology used, associated cause(s), and connected emotions/psychological-states were coded. Since climate grief is not a universally used term, we define "climate grief terminology" as any terminology used to describe the grief and loss connected to climate change. Associated cause(s) are the environmental or circumstantial issues that a person or group of people associated with their experiences of climate grief. These were coded to better understand more specifically what occurs to cause people to experience climate grief. These issues were only coded when people explicitly stated what they felt was causing their climate grief, and described what was occurring in their lives at the time. We consider "connected emotion/psychological state" as any specifically mentioned emotion or psychological state occurring alongside the experience of climate grief. These were also coded to better understand the complex experience of climate grief and to identify what events and emotions are connected to it.

\subsection{Stage 5: Collating, summarizing and reporting the results}

This stage involved understanding, summarizing and presenting the typology in a way that effectively demonstrated the range of vocabularies and rituals. Definition tables were created to inform working mind maps, and charts were created to present primary, secondary, and tertiary levels (themes, types, and subtypes) of the typology in a cohesive way. The resulting visuals of these processes are present in the following section.

[2] Universities involved in the project are Dalhousie University, NSCAD University, The University of Winnipeg, the University of Manitoba, and the University of New Brunswick.

${ }^{[3]}$ We acknowledge that such political boundaries are a colonial construct and do not represent the traditional territories of Indigenous nations.

${ }^{[4]}$ Due to limited French content in the Dalhousie Eco-Art Interactive map, Google Images was added in the French search protocol to expand the search.

\section{Results}

\subsection{Bibliometrics}

From the scoping review, 52 English sources and 77 French sources were found and coded. The earliest English source was published in 1990 and the remainder of sources found were from the last 12 years, with the majority of the sources being from the past three years (Figure 1). From the 77 sources analyzed for the French scoping review, the earliest source found was published in 2015, with the majority of sources being from the years 2019 and 2020 (Figure 1). The study selection step for the scoping review 
concluded before the end of the year 2020; as a result, the lower numbers in 2020 compared to 2019 does not necessarily mean that sources expressing climate grief were less frequent in 2020.

The sources were categorized by location based on their area of focus - whether a province, territory, region, Canada as a whole, or Canada and beyond. If they did not have a particular focus but were from a Canadian source, they were categorized based on their location of origin. Sources that referred specifically to Indigenous peoples' territory were categorized as such. In this case, sources referring uniquely to Inuit communities or Inuit land were categorized under Inuit Nunangat (Indigenous Peoples Atlas of Canada, n.d.). For the English sources, Canada as a whole was the most common area of focus, with British Columbia and Newfoundland and Labrador tied for the second most common (Figure 2). For the French sources, Québec was the most common location of origin/area of focus, with Canada as a whole being second.

\subsection{Climate grief terminology}

Canadians use various terms to express climate grief. The most common English "climate grief" terminology used was ecological (eco) grief, which is largely due to the work of Dr. Cunsolo at Memorial University. The second and third most common were solastalgia and climate grief. There was also ecological anxiety/loss and environmental loss/grief/ melancholia/dread. The most common term expressed in the collected French sources was by far écoanxiété (ecoanxiety), particularly in media and social media sources. This was followed by solastalgie (solastalgia) as well as deuil écologique (ecological grief). Other terms used include angoisse climatique (climatic anguish), angoisse écologique (ecological anguish), anxiété écologique (ecological anguish), écoconfusion (eco-confusion), écoémotions (eco-emotions), and tristesse écologique (ecological sadness). Certain terms like solastalgia and ecological grief cross-over between the two languages, while other terms like angoisse climatique appear only within the bounds of one language.

\subsection{Typology for climate grief in Canada}

The themes of the vocabularies and rituals used to express climate grief in Canada are: peer-reviewed research, grey literature, guiding frameworks, education, media, religious/spiritual practices, mental health support, social action gatherings, and artistic expression (Figure 3). Definitions for each vocabulary and ritual in this typology along with a complete list of sources found for each vocabulary and ritual are provided as an electronic supplement.

Each theme overarches two or more secondary-level types of vocabularies and rituals. For peer-reviewed research, this includes books and a focus on conducting both primary and secondary research to better understand this phenomenon. Under primary research, subtypes of using interviews and/or focus groups as a way to conduct research on this topic were found, and with secondary research, we found research conducted via literature reviews, scoping reviews, and editorials on the topic of climate grief as well. For the theme of grey literature, types found were an unpublished master's thesis and organizational reports. 
These were categorized as grey literature as they were evidence-informed, not published in academia, and created by a business/organization for a small or specific audience.

Guiding frameworks found were policy tools, position statements, and recommendations. These were created by organizations and governing bodies that sought to change their system of principles, guidelines, or rules to address climate grief. Under policy tools, we identified an impact monitoring tool employed by Québec's provincial government which monitors the impacts of climate change on mental health, and under recommendations, we found an informational poster where an organization sought to inform their members on how climate grief may impact their everyday work. For the theme of education, the types include museums, webinars, and conferences, which were each used to help people learn about the phenomenon. When people used museums for education, they used exhibitions to inform the patrons.

For people who expressed their climate grief through social action gatherings, they used idea exchanges, acts of civil resistance, and acts of community service. Subtypes of civil resistance took the form of strikes such as the global climate strike, and demonstrations like the climate marches. For the theme of mental health support, the types that were found include a help-line, and forming support groups for people to seek aid for their experiences with climate grief. Certain support groups were shown to have a more specific subtype called sharing circles, where the focus was not just to give people a safe space to share their experiences of climate grief, but also to help them gain tools and grow in mental and emotional resiliency.

The two types of religious/spiritual practices found were prayer and dance. Hoop dancing, an Indigenous dance often performed at healing ceremonies (Spence 2016), was identified as a subtype of dance under this theme. Performing arts as a type of artistic expression also has the subtype of dance, but not for the purpose of religious/spiritual expression. Thus, they were categorized as separate practices. The theme of artistic expression, whereby people expressed their experiences of climate grief through art, was divided into three types: visual art, performing arts, and literature. The subtypes of performing arts are dance, music, spoken word, and theater, and the subtypes of visual arts are painting, photography, printmaking, textiles, installation art, and sculpture. The only subtype found for literature was poetry.

Lastly, the theme of media for mass communication had the largest range of types and subtypes. The types of media with climate grief vocabularies and rituals are print/electronic media, broadcast media, social media, and film. Within broadcast media, podcasts, news, and radio were all subtypes found to be reporting on or discussing the phenomenon of climate grief. The subtypes of film that we found completing the same task were documentary and short film. Within print/electronic media, the subtypes of books, magazines, perspective pieces, and news were found; in this case, news refers to media distributed in print form (e.g., newspaper, electronic news articles), while the latter subtype of news refers to broadcast news (e.g., televised news segments). Lastly, social media creations expressing climate grief took various forms, which we categorized into the subtypes of microblogging (e.g., Twitter), photo sharing (E.g., Instagram), social networking (e.g., Facebook), and video sharing (e.g., YouTube). These 
social media platforms are multi-purpose and can overlap with subtypes outside of the one they were categorized in (e.g., video sharing can now also take place on Instagram and Facebook); however, they were divided based on their primary form of communication.

Overall, the typology represented in Figure 3 demonstrates how climate grief may be an increasingly common experience for Canadians as it is being expressed in numerous ways and in various locations throughout Canadian society.

\subsection{Associated emotions, associated causes and solutions}

The associated emotions and/or psychological states were numerous in both languages. The languages are combined to show the range rather than the frequency. Feelings/states of anxiety, fear, powerlessness (impuissance), anger, depression, stress, post-traumatic stress, sadness, and loss were most commonly expressed alongside climate grief. Other emotions and psychological states associated with climate grief were anguish (angoisse), feeling paralyzed, worry, suicide or suicidal ideation, guilt, despair, crushing (écrasant), exhaustion, panic, frustration, and hopelessness. Though much less frequent, a few of the sources expressed feelings of hope associated with their experiences of climate grief.

The associated causes - the environmental or circumstantial issues that a person or group of people associated with their experience of climate grief - were numerous. The most frequent issues were environmental phenomena, particularly gradual, physical changes caused by climate change including warming temperatures, sea ice melting and a decrease in duration of sea ice, rising sea levels, changes in weather and precipitation, coastal erosion, environmental degradation, melting permafrost, ocean acidification, a decrease in air quality, and an increase in extreme weather events. Extreme weather events such as floods, wildfires and the resulting smoke, severe storms, and drought - as well as life-changing consequences that result from these events such as evacuation, damage, and displacement - were also connected to expressions of climate grief. The health consequences of these events, as well as their tendency to perpetuate racial and economic inequities, were acknowledged and/or discussed several times throughout the sources. The theme of loss was prominent in expressions of grief, including loss of cultural identity, of time on and connection with land, of species, of landscapes and physical ecology, and the anticipation of these losses in the future. A lack of climate change action from family members, government, industry, and society in general was a common thread across many sources, and it was often expressed as an exacerbator of climate grief. Other exacerbators were experiencing limited resources to take climate action, increases in resource extraction, and feeling overburdened with bad news about the climate. Certain sources expressed how young people were disproportionately impacted by climate grief, and some expressed how this impacted their life choices such as what they choose to eat every day, which career they go into, and choosing to not have kids until the climate crisis has been addressed.

A pattern noted in the French sources discussing climate grief was the frequent inclusion of solutions for addressing or managing this phenomenon. A commonly proposed solution to help manage feelings of climate grief was to get involved in climate action through everyday actions to reduce climate impacts 
and/or through activism. Another commonly proposed solution was to share experiences of climate grief with others through therapy (specifically cognitive behavioural therapy) or simply by talking to close ones and/or others with similar experiences, such as in sharing circles. Other solutions included educating others about the climate crisis, and reducing the consumption of negative information. Some mentioned that simply focusing more on solutions and sharing positive messages and reducing negative information can be beneficial in itself. Similar discussions on solutions were present in English sources, but were less prominent compared to the French sources included in this study.

\section{Discussion And Conclusions}

With extreme weather events and visible changes in landscape due to a changing climate becoming more evident in recent years (e.g., NRC 2020), it is no surprise that the majority of the 129 sources found through this scoping review have been published between 2018 and 2020. This increasing number speaks to the likelihood that climate grief is an increasingly common phenomenon (Cunsolo and Ellis 2018), and one that Canadians are learning to express. As for the location of focus or origin of these sources, all provinces and territories except for Saskatchewan are represented. Though earlier studies on climate grief in Canada have focused on northern areas such as Newfoundland and Labrador, where climate change first produced significant changes in landscapes (Cunsolo-Willox et al. 2013), the presence of expressions of climate grief throughout Canada, particularly where there have been an increasing amount of extreme events (e.g., wildfires in British Columbia) demonstrates the increasing reaches of climate change and its consequential impact on Canadians. French sources expressing climate grief were also found throughout Canada, in just over half of provinces and territories. Though Québec was the most frequent location of origin for French sources, this is not necessarily due to expressions of climate grief being more frequent in the province, but rather because the province is the only province/territory with French as its only official language. That being said, it is clear that discussions on climate grief, particularly expressed as écoanxiété, have an increasing presence in the mostly French-speaking province.

As exemplified by the typology (Figure 3) there are a variety of ways that people in Canada are expressing, reacting to, and processing grief associated with climate change. Some of the major existing terms related to climate grief, such as solastalgia and ecological grief, first appear in academia and peerreviewed literature (Albrecht 2005; Cunsolo and Ellis 2018). Our typology shows that these terms (as well as others) have now spread outside of academia and are being utilized to describe climate grief in educational settings, in media, and in various forms of artistic expression. Climate-related art can provide an opening for people to process and be open to change (Bentz and O'Brien 2019) - the diversity of artistic mediums through which climate grief is being expressed in Canada provides a glimpse for how art may be an important medium through which Canadians are grappling with the phenomenon. The presence of mental health supports demonstrate that Canadians are asking for and creating spaces where experiences of climate grief can be processed. The presence of concrete expressions of climate grief, such as social action showcases other ways through which Canadians are creating spaces, processes and actions where feelings of climate grief can be recognized and felt. Finally, the presence of 
vocabularies related to climate grief in guiding frameworks and organizational reports showcases that it is beginning to be integrated into institutional frameworks.

Based on our preliminary literature search, it was not surprising to find that ecological grief was the most commonly used term in English. Solastalgia and climate grief were also commonly used, which highlights the range of terminologies for this shared experience. Though many of the terms used to describe climate grief cross-over between the two languages (e.g. solastalgia, ecological grief), the term écoanxiété is by far the most commonly utilized term in the French language, particularly in popular media settings such as social media where the terms solastalgie and deuil écologique are for the most part absent in discussions by Canadian users. Unlike other terminology, this term on its own does not explicitly refer to grief or loss associated with climate change, but rather feelings of anxiety associated with climate grief (Albrecht 2011). However, anxiety itself is intertwined with grief in general (e.g. Yan et al. 2021), and it is a key process present in climate grief associated with anticipated future losses (Cunsolo and Ellis 2018). In some French sources, the terms écoanxiété and solastalgie are utilized interchangeably to describe the psychological impacts of climate change (e.g. Boule 2019; St-Martin 2019). This indicates that these terms may not be differentiated in French-Canadian culture, and as a result, écoanxiétémay be utilized more frequently as its meaning is more intuitive than the term solastalgie.

The numerous associated emotions and psychological states identified alongside expressions of climate grief speak to the complexities of the emotional and psychological processes that are intertwined with this experience. Some of these identified emotions and psychological states overlap with Albrecht's (2005) findings of manifestations of solastalgia, including fear, powerlessness, frustration, as well as physical and mental distress potentially leading to substance use, serious psychiatric disorders, and suicide. As for the associated causes, with Canada warming at double the global rate and the north warming even faster (Bush and Lemmen 2019), it was not surprising to find that the most common associated causes were connected to warming temperatures, heat waves, and the decline of sea ice thickness and duration. Some of the associated causes identified in our research, particularly extreme weather events, gradual environmental changes, displacement, and resource extraction, overlap with Galway et al.'s (2019) findings on sources of environmental change resulting in solastalgia. Other similar findings include Albrecht's (2005) observation that loss of ecosystem health and community, as well as political powerlessness, contribute to experiences of solastalgia, and Cunsolo and Ellis' (2018) identification of loss of ecology, of identity, and anticipated loss as pathways towards ecological grief. The range in vocabulary, associated causes, and associated emotions and psychological states, show that climate grief is a complex experience that should not be over-simplified. Even so, the repeating themes in these categories provide evidence of common threads between these experiences, and that individuals in Canada are not alone in their experiences of climate grief.

The differences in use of terminology between languages and the overwhelming presence of potential solutions present in the French-Canadian sources provides an example of how cultural factors, including the history of a culture, will inform how people experience and discuss climate grief. At various times 
throughout Canada's history (including pre-confederation), French-Canadians have experienced what Wohl et al. (2010) call perceived extinction threat, whereby, due to a history of antagonistic policies and minority status in Canada, the future existence of French-Canadian culture has been in a state of threat. Anxiety, an emotion that focuses on future threats of negative events, is an emotion that also occurs when a group's identity is threatened (Wohl et al. 2010). This experience of anxiety due to possible threatrelated outcomes leads people to invest time and effort to prepare for and avoid these potential negative events (Wohl et al. 2010), and in this context, intentions for collective action are more likely to appear (Jaśkiewicz et al. 2021). Our findings of the prominent focus on feelings of anxiety as they are related to climate grief (éco-anxiété), as well as the focus on solutions to these feelings, may relate to this history. Since climate change also represents a threat for future loss, experiences of climate grief may overlap with a culture's history of threat, and as a result, have an impact on how a group of people experience and respond to climate grief. It is important to note that climate change does pose a very real threat to cultural loss throughout Canada, especially for Indigenous communities who maintain strong connections and traditions tied to the land. ...

More research needs to be done in order to better understand and support those who are experiencing climate grief. If governments across Canada are not prepared for the effects that climate change will continue to have on wellbeing, solutions will remain reactionary rather than proactive. This is currently being seen in the COVID-19 pandemic. Though the COVID-19 crisis represents a very immediate threat compared to climate change which is more longer-term/future-oriented (as well as increasingly being experienced in real time), this crisis provides a look into existing infrastructure and government responses available to support Canadians through an international crisis. According to the Centre of Addiction and Mental Health, they have seen an immense psychological toll on their students and staff, and increasing stress and anxiety related to fear for their health and the health of their loved ones (CAMH 2020). Recent projections predict unemployment from COVID-19 could result in an additional 418-2114 suicides in Canada (Mclntyre and Lee 2020). Planning for another crisis may prove challenging while still in the midst of another, however the growing body of data about the impacts of climate change on mental health and overall wellbeing can assist governments in addressing predicted consequences of climate change before more acute events occur.

Our research contributes to the growing literature on climate grief, which will be important for developing appropriate policy and will be essential for creating appropriate future interventions in health, education, planning and other sectors. The typology is adaptive and should evolve with time in order to maintain a clear and accurate representation of climate-related vocabularies and rituals across Canada.

\section{Limitations}

It is important to acknowledge that like all research this research had limitations. English and French were the only languages used in searches and in data collection and thus prevented many of the languages and cultures from being present in the results. Only content that was published or documented online 
were used in the typology and may be a reason why there are not more examples of typically undocumented rituals such as religious/ spiritual practices.

\section{Statements And Declarations}

Climate grief, climate change, mental health, wellbeing, scoping review, Canada, typology, solastalgia

Funding: The research was supported by a New Frontiers in Research Fund (NFRF) Explore Grant (\#201900194), as well as through an internship (for Boyd) through EcoCanada.

Conflicts of interest/Competing interests: The authors declare no conflicts of interest.

Availability of data and material: The full list of sources used in the typology is provided in the supplementary materials for this paper.

\section{References}

1. Albrecht G (2005) Solastalgia, a new concept in human health and identity. Philosophy Activism Nature 3:41-44.

2. Albrecht G (2011) Chronic environmental change: Emerging "psychoterratic" syndromes. In:

3. Weissbecker I (ed.) Climate change and human well-being: Global challenges and opportunities, International and cultural psychology, Springer, New York, pp 43-56. https://doi.org/10.1007/978-14419-9742-5

4. Arksey H, O'Malley L (2005) Scoping studies: Towards a methodological framework.

5. International Journal of Social Research Methodology 8(1):19-32. https://doiorg.ezproxy.library.dal.ca/10.1080/1364557032000119616

6. Bentz J, O'Brien K (2019) ART FOR CHANGE: Transformative learning and youth empowerment in a changing climate. Elements: Science of the Anthropocene 7:52. https://doi.org/10.1525/elementa.390

7. Bipolar UK (2006) Bipolar-the facts. https://www.bipolaruk.org/faqs/bipolar-the-facts.

8. Boule, M (2019, April 2) L'écoanxiété est le nouveau mal lié aux changements climatiques. Vice.https://www.vice.com/fr/article/nexna8/lecoanxiete-est-le-nouveau-mal-lie-au-rechauffementclimatique

9. Bryant A (2019) What is Climate Grief? Climate \& Mind.http://www.climateandmind.org/what-isclimate-grief

10. Bush E, Lemmen DS (2019) Canada's Changing Climate Report. Government of

11. Canada. https://www.nrcan.gc.ca/sites/www.nrcan.gc.ca/files/energy/Climatechange/pdf/CCCR_FULLREPORT-EN-FINAL.pdf. Accessed 28 June 2021 
12. Campbell D (2012, June 27) People with bipolar disorder may wait 13 years for diagnosis. The Guardian. https://www.theguardian.com/society/2012/jun/27/bipolar-disorder-diagnosissurveyCentre for Addiction and Mental Health (CAMH) (2020) Mental health in Canada: Covid-19 and beyond. http://www.camh.ca/-/media/files/pdfs--public-policy-submissions/covid-and-mh-policypaper-pdf.pdf. Accessed 28 June 2021

13. Cunsolo A, Ellis NR (2018) Ecological grief as a mental health response to climate change-related loss. Nature Climate Change 8:275-281. DOI:10.1038/s41558-018-0092-2

14. Cunsolo A, Harper SL, Minor K, Hayes K, Williams KG, Howard C (2020) Ecological grief and anxiety: The start of a healthy response to climate change? The Lancet Planetary Health 4:261-263. https://doi.org/10.1016/S2542-5196(20)30144-3

15. Cunsolo-Willox A, Harper S, Ford L, Edge J, Landman D, Houle V, Wolfrey S (2013) Climate change and mental health: An exploratory case study from Rigolet, Nunatsiavut, Canada. Climatic Change 121(2):255-270. https://doi.org/10.1007/s10584-013-0875-4 Education for Sustainable Research Group (ESRG) (n.d.) Eco-Art: An Interactive Map. https://dalspatial.maps.arcgis.com/apps/MapSeries/index.html? appid $=5 c 5862 c 26 e 0744 d d 8 c a e c 43 e 6 b 2 b 3516$. Accessed 1 May 2020

16. Elo S, Kyngäs H (2007) The qualitative content analysis process. Journal of Advanced Nursing 62(1):107-115. doi: 10.1111/j.1365-2648.2007.04569.x Galway LP, Beery T, Jones-Casey K, Tasala K (2019) Mapping the solastalgia literature: A scoping review study. International Journal of Environmental Research and Public Health 16:2662. doi:10.3390/ijerph16152662

17. Indigenous Peoples Atlas of Canada (n.d.) Inuit Nunangat. https://indigenouspeoplesatlasofcanada.ca/article/inuit-nunangat/

18. IPCC (2019) Summary for policymakers. In: Shukla PR, Skea J, Calvo Buendia E,

19. Masson-Delmotte V, Pörtner H-O, Roberts DC, Zhai P, Slade R, Connors S, van Diemen R, Ferrat M, Haughey E, Luz S, Neogi S, Pathak M, Petzold J, Portugal Pereira J, Vyas P, Huntley E, Kissick K, Belkacemi M, Malley J (eds) Climate change and land: an IPCC special report on climate change, desertification, land degradation, sustainable land management, food security, and greenhouse gas fluxes in terrestrial ecosystems. In press

20. Jaśkiewicz M, Besta T, Borchet J (2021) Collective angst and group continuity as predictors of collective action for progressive city politics. Group Processes \& Intergroup Relations:1-22. DOI: $10.1177 / 1368430220987603$

21. Kimmerer RW (2013) Braiding Sweetgrass: Indigenous Wisdom, Scientific Knowledge, and the Teachings of Plants. Milkweed Editions, Minneapolis.

22. Mclntyre RS, Lee Y (2020) Projected increases in suicide in Canada as a consequence of COVID-19. Psychiatry Research 290:1-3. doi.org/10.1016/j.psychres.2020.113104 Natural Resources Canada (NRC) (2020) Indicator: Forest fires. Government of Canada. https://www.nrcan.gc.ca/our-naturalresources/forests-forestry/state-canadas-forests-report/how-does-disturbance-shapecanad/indicator-forest-fires/16392. Accessed 28 June 2021 
23. Pihkala P (2020) Climate grief: how we mourn a changing planet. BBC Online. https://www.bbc.com/future/article/20200402-climate-grief-mourning-loss-due-to-climate-change

24. Richards EP (2018) The societal impacts of climate anomalies during the past 50,000 years and their implications for solastalgia and adaptation to future climate change. Houston Journal of Health Law \& Policy 18:131-168

25. Spence S (2016) My story. https://shanleyspence.com/mystory/. Accessed 5 September 2020

26. St-Martin C (2019, December 2) L'écoanxiété, ou l'anxiété à l'ère de Zuckerberg et des

27. changements climatiques. L'Amnésique. https://amnesique.com/2019/12/02/lecoanxiete-oulanxiete-a-lere-de-zuckerberg-et-des-changements-climatiques-par-cleo-st-martin/

28. Thurton D (2017, August 7) Burned twice: Family who lost home in Fort McMurray wildfire loses another in B.C. wildfire. CBC news. https://www.cbc.ca/news/canada/edmonton/burned-twice-fortmcmurray-bc-wildfire-homes-destroyed-by-1.4236584

29. Wohl MJA, Branscombe NR, Reysen S (2010) Perceiving your group's future to be in jeopardy: Extinction threat induces collective angst and the desire to strengthen the ingroup. Personality and Social Psychology Bulletin 36(7):898-910. DOI: 10.1177/0146167210372505

30. Yan B, Lo RSK, Chow AYM (2021) The role of post-loss anxiety in the development of depressive symptoms and complicated grief symptoms: A longitudinal SEM study. Journal of Affective Disorders 281:649-656. https://doi.org/10.1016/j.jad.2020.11.096

\section{Figures}




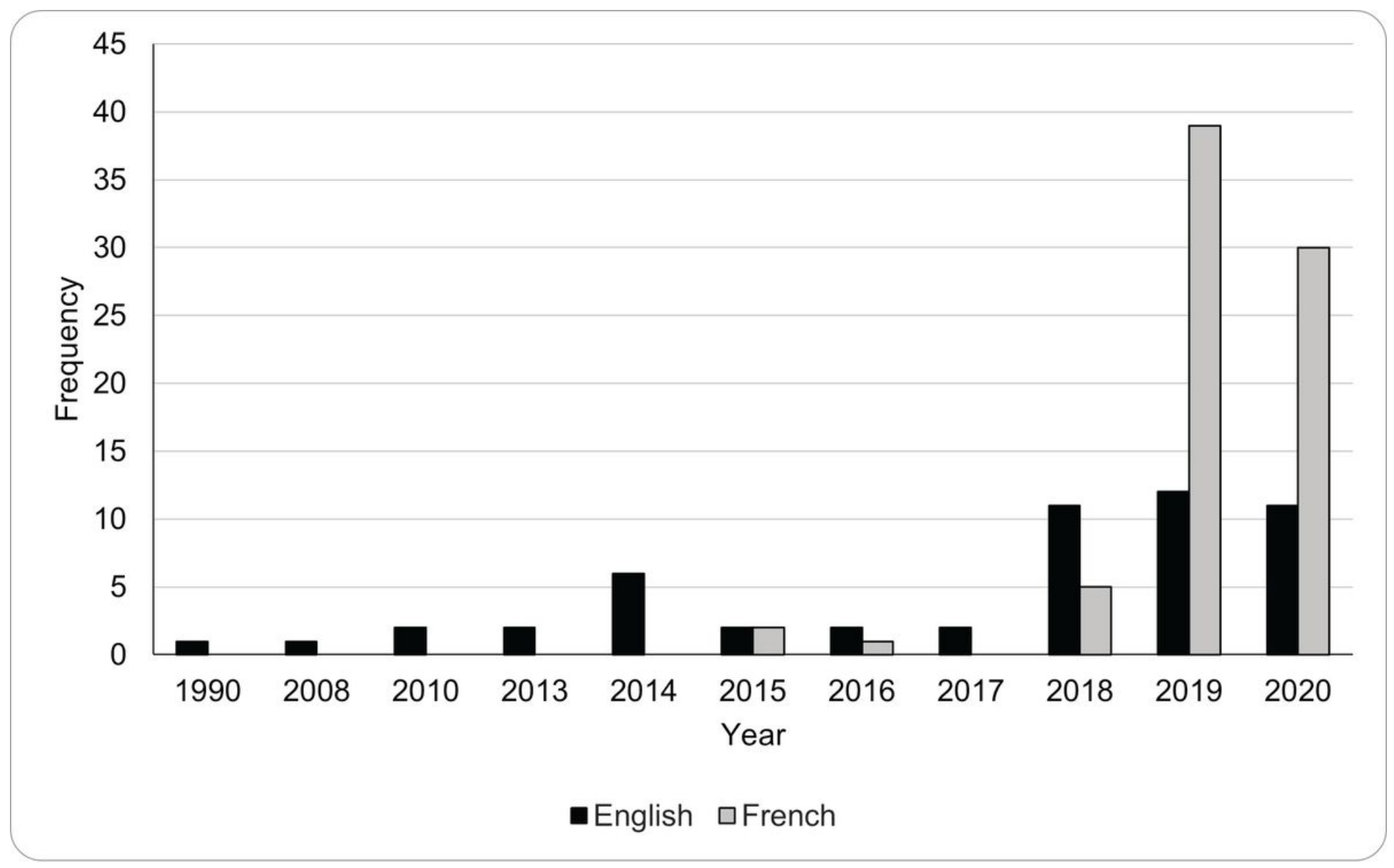

Figure 1

Frequency of sources by year published/created. 


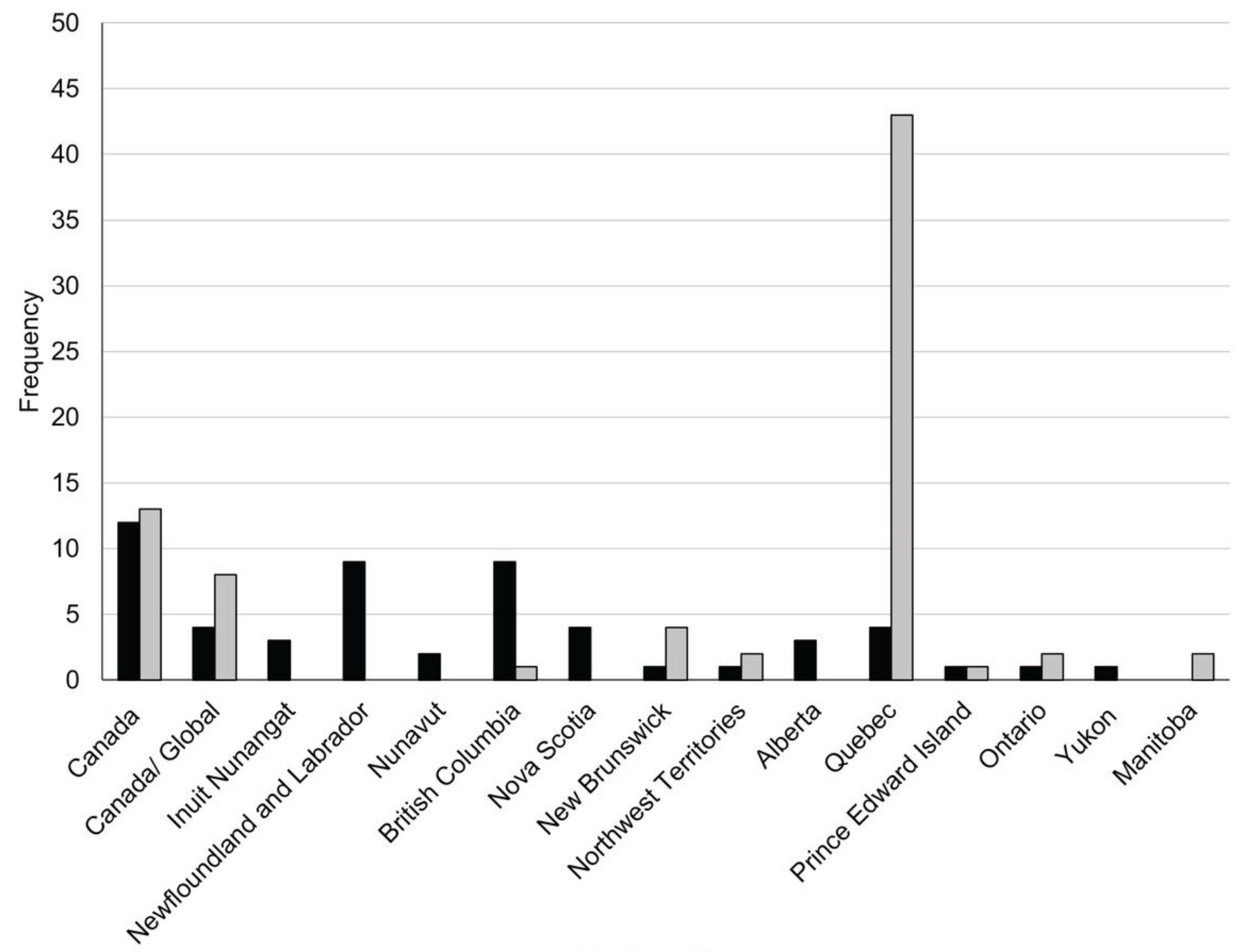

Region of focus

-English $\square$ French

Figure 2

Frequency of sources by region of focus/ location of origin 


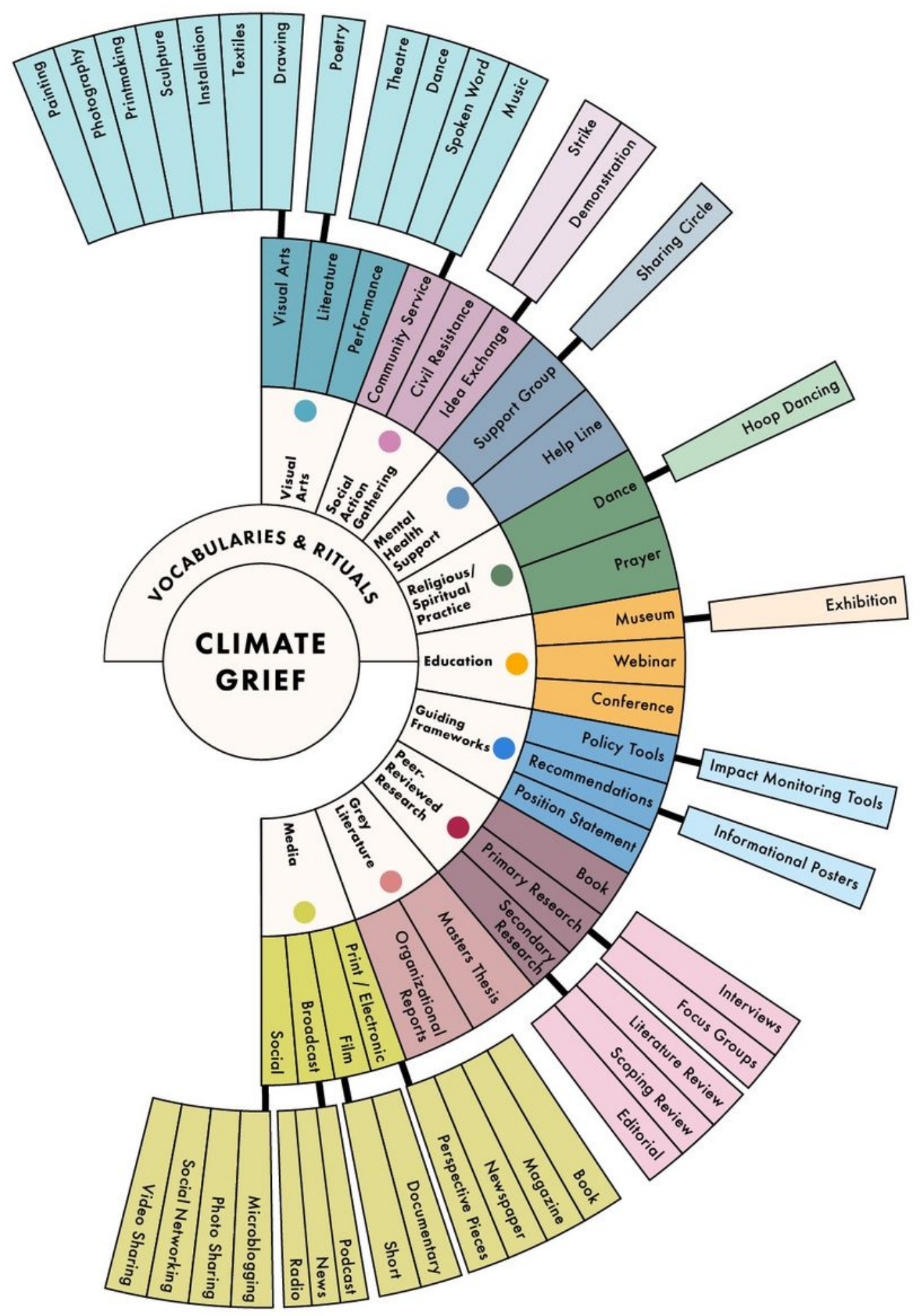

Figure 3

Visual depiction of the types of vocabularies and rituals for climate grief in Canada

\section{Supplementary Files}

This is a list of supplementary files associated with this preprint. Click to download. 
- Electronicsupplementtableandreferences12221.docx 